\title{
Effects of intraoperative lung-protective ventilation on clinical outcomes in patients with traumatic brain injury: a randomized controlled trial
}

Lulu Jiang ${ }^{1,2}$, Yujuan Wü ${ }^{3}$ Yang Zhang ${ }^{1,2}$, Dahao $\mathrm{Lu}^{2}$, Keshi Yan² and Ju Gao ${ }^{2^{*}}$

\begin{abstract}
Background: Secondary lung injury is the most common non-neurological complication after traumatic brain injury $(\mathrm{TBI})$. Lung-protective ventilation (LPV) has been proven to improve perioperative oxygenation and lung compliance in some critical patients. This study aimed to investigate whether intraoperative LPV could improve respiratory function and prevent postoperative complications in emergency TBI patients.

Methods: Ninety TBI patients were randomly allocated to three groups (1:1:1): Group A, conventional mechanical ventilation [tidal volume (VT) $10 \mathrm{~mL} / \mathrm{kg}$ only]; Group B, small VT (8 $\mathrm{mL} / \mathrm{kg})+$ positive end-expiratory pressure (PEEP) $\left(5 \mathrm{cmH}_{2} \mathrm{O}\right)$; and Group C, small VT $(8 \mathrm{~mL} / \mathrm{kg})+\operatorname{PEEP}\left(5 \mathrm{cmH}_{2} \mathrm{O}\right)+$ recruitment maneuvers (RMs). The primary outcome was the incidence of total postoperative pulmonary complications; Secondary outcomes were intraoperative respiratory mechanics parameters and serum levels of brain injury markers, and the incidence of each postoperative pulmonary and neurological complication.

Results: Seventy-nine patients completed the final analysis. The intraoperative $\mathrm{PaO}_{2}$ and dynamic pulmonary compliance of Groups B and C were higher than those of Group A $(P=0.028 ; P=0.005)$, while their airway peak pressure and plateau pressure were lower than those of group $A(P=0.004 ; P=0.005)$. Compared to Group $A$, Groups B and C had decreased 30-day postoperative incidences of total pulmonary complications, hypoxemia, pulmonary infection, and atelectasis ( $84.0 \%$ vs. $57.1 \%$ vs. $53.8 \%, P=0.047 ; 52.0 \%$ vs. $14.3 \%$ vs. $19.2 \%, P=0.005$; $84.0 \%$ vs. $50.0 \%$ vs. $42.3 \%, P=0.006 ; 24.0 \%$ vs. $3.6 \%$ vs. $0.0 \%, P=0.004)$. Moreover, intraoperative hypotension was more frequent in Group $C$ than in Groups $A$ and $B(P=0.007)$. At the end of surgery, the serum levels of glial fibrillary acidic protein and ubiquitin carboxyl-terminal hydrolase isozyme $L 1$ in Group B were lower than those in Groups $A$ and $C(P=0.002 ; P<0.001)$. The postoperative incidences of neurological complications among the three groups were comparable.
\end{abstract}

Conclusions: Continuous intraoperative administration of small VT + PEEP is beneficial to TBI patients. Additional RMs can be performed with caution to prevent disturbances in the stability of cerebral hemodynamics.

\footnotetext{
* Correspondence: 178201049@csu.edu.cn

${ }^{2}$ Department of Anesthesiology, Northern Jiangsu People's Hospital, Clinical

Medical School, Yangzhou University, 98\# Nantong West Road, 225001

Yangzhou, China

Full list of author information is available at the end of the article
}

(C) The Author(s). 2021 Open Access This article is licensed under a Creative Commons Attribution 4.0 International License, which permits use, sharing, adaptation, distribution and reproduction in any medium or format, as long as you give appropriate credit to the original author(s) and the source, provide a link to the Creative Commons licence, and indicate if changes were made. The images or other third party material in this article are included in the article's Creative Commons licence, unless indicated otherwise in a credit line to the material. If material is not included in the article's Creative Commons licence and your intended use is not permitted by statutory regulation or exceeds the permitted use, you will need to obtain permission directly from the copyright holder. To view a copy of this licence, visit http://creativecommons.org/licenses/by/4.0/. The Creative Commons Public Domain Dedication waiver (http://creativecommons.org/publicdomain/zero/1.0/) applies to the data made available in this article, unless otherwise stated in a credit line to the data. 
Trial registration: Chinese Clinical Trial Registry (ChiCTR2000038314), retrospectively registered on September 17, 2020.

Keywords: Traumatic brain injury, Lung-protective ventilation, Postoperative pulmonary complications, Optic nerve sheath diameter, Glial fibrillary acidic protein, Ubiquitin carboxyl-terminal hydrolase isozyme L1

\section{Background}

Traumatic brain injury (TBI) is a major medical and socioeconomic problem. Over 50 million people worldwide experience TBI every year, and the morbidity has increased in the past decade [1]. TBI causes a wide range of systemic effects. It was reported that $89 \%$ of severe TBI patients experienced at least one non-neurological complication, of which $81 \%$ developed respiratory dysfunction, including $23 \%$ of respiratory failure cases. Hence, respiratory complications are prevalent nonneurological disorders experienced after TBI [2]. In addition, neural and humoral regulation after injury leads to an attenuated response of lung tissues to stress $[3,4]$, thus increasing the risk of pulmonary complications, especially pulmonary infection, neurogenic pulmonary edema (NPE), ventilator-associated lung injury (VALI), and atelectasis.

In general anesthesia, tidal volume (VT) was usually set at $10-15 \mathrm{~mL} / \mathrm{kg}$ corrected body weight (CBW) before, which is higher than that of most mammals with spontaneous respiration. High VT ventilation may cause alveolar overdistention, inflammatory mediator spillover, and VALI. Currently, lung-protective ventilation (LPV) is defined as $\mathrm{VT} \leq 8 \mathrm{~mL} / \mathrm{kg}$, positive end-expiratory pressure $(\mathrm{PEEP}) \geq 5 \mathrm{cmH}_{2} \mathrm{O}$, and airway plateau pressure (Pplat) $\leq 30 \mathrm{cmH}_{2} \mathrm{O}$, which is recognized as the optimal ventilation mode for patients with acute respiratory distress syndrome (ARDS) in the intensive care unit (ICU) [5]. In view of satisfactory application of LPV in ARDS patients, perioperative lung protection in the operating room has also been highlighted by anesthesiologists.

Various factors contribute to the complex interactions between mechanical ventilation (MV) and cerebral hemodynamics during surgery. Many clinical trials or meta-analyses have found that perioperative application of LPV can improve intraoperative oxygenation and lung compliance, and relieve postoperative pulmonary complications (PPCs). However, PEEP or recruitment maneuvers (RMs) may disrupt the stability of cerebral hemodynamics in emergency TBI patients, who are often excluded from these studies. Whether perioperative LPV is also beneficial to these patients requires explorations. A recent retrospective study involving 28,644 TBI patients in the ICU showed no significant changes in intracranial pressure (ICP) and cerebral perfusion pressure (CPP) after applying LPV, indicating the safety of respiratory support in TBI patients [6].
Here, we conducted a randomized controlled trial with the hypothesis that intraoperative use of LPV can improve respiratory function and prevent postoperative complications in TBI patients. The primary aim was to assess the incidence of total PPCs in TBI patients treated with LPV. The secondary aims were to investigate intraoperative respiratory mechanics parameters and serum levels of brain injury markers, and the incidence of each postoperative pulmonary and neurological complication.

\section{Methods}

\section{Study design, approvals and registration}

A single-center, randomized controlled study involving 90 TBI patients was approved by the Ethics Committee of Northern Jiangsu People's Hospital $(2,019,113)$. Informed consent was obtained from patients or their relatives. The trial was retrospectively registered at the Chinese Clinical Trial Registry (ChiCTR2000038314) on 17/09/2020.

\section{Patients}

TBI patients aged 18-65 years who underwent emergency intracranial evacuation of hematoma were enrolled. No limitation on sex was set. Their body mass index (BMI) ranged from 18.5 to $29.9 \mathrm{~kg} / \mathrm{m}^{2}$, and they were American Society of Anesthesiologists (ASA) Classification III or IV.

Patients with a history of mental diseases or other neurological disorders (epilepsy, dementia, cerebrovascular malformation, etc.), severe cardiovascular diseases (valvular heart disease, pericarditis, cor pulmonale, etc.), and severe hepatic or renal insufficiency (cirrhosis, chronic renal failure, nephrotic syndrome, etc.), were excluded. Patients who had stroke, myocardial infarction or major surgery within three months and refused to participate were also excluded.

Patients were assigned by computer-generated randomized sequence to three groups (1:1:1): Group A (conventional MV), Group B (small VT $+5 \mathrm{cmH}_{2} \mathrm{O}$ PEEP), and Group $\mathrm{C}$ (small VT $+5 \mathrm{cmH}_{2} \mathrm{O}$ PEEP + $\mathrm{RMs}$ ). The random allocation scheme was sealed by the principal investigator in opaque envelopes. Two experienced anesthesiologists blinded to the random allocation enrolled eligible participants, and the other two assigned participants to interventions. 


\section{Anesthesia}

Midazolam $(0.05 \mathrm{mg} / \mathrm{kg})$, sufentanil $(0.5 \mu \mathrm{g} / \mathrm{kg})$, propofol (1-2 $\mathrm{mg} / \mathrm{kg})$, and cisatracurium $(0.15-0.20 \mathrm{mg} / \mathrm{kg})$ were intravenously injected for anesthesia induction. After tracheal intubation, the anesthesia machine was connected to start MV.

Inhalation of $2 \%$ sevoflurane during operation, and intravenous pump injection of remifentanil $(0.1-0.3 \mu \mathrm{g} /$ $\mathrm{kg} / \mathrm{min})$, dexmedetomidine $(0.01 \mu \mathrm{g} / \mathrm{kg} / \mathrm{min})$, and cisatracurium $(5 \mu \mathrm{g} / \mathrm{kg} / \mathrm{min})$ were performed for anesthesia maintenance, the dose of which was adjusted according to the depth of anesthesia. Vasoactive drugs were applied if cyclic fluctuations occurred during surgery.

\section{Mechanical ventilation}

All patients received MV after tracheal intubation under the same general anesthesia management. Immediately after intubation, volume-controlled ventilation was applied in three groups with VT $10 \mathrm{~mL} / \mathrm{kg}$ CBW, inspiration/expiration $1: 2$, fraction of inspired oxygen $100 \%$, oxygen flow $2 \mathrm{~L} / \mathrm{min}$, and no PEEP or RMs. Five minutes later, the parameters of Groups B and C were continuously adjusted to $8 \mathrm{~mL} / \mathrm{kg} \mathrm{CBW}$ of $\mathrm{VT}$ and 5 $\mathrm{cmH}_{2} \mathrm{O}$ PEEP. Patients in Group $\mathrm{C}$ received two RMs before opening and after closing the endocranium. Briefly, RMs were performed to maintain an airway pressure of $30 \mathrm{cmH}_{2} \mathrm{O}$ for $30 \mathrm{~s}$. During the operation, the respiratory rate was adjusted according to arterial blood gas analysis to maintain end-tidal carbon dioxide partial pressure $\left(\mathrm{P}_{\mathrm{ET}} \mathrm{CO}_{2}\right)$ at $30-35 \mathrm{mmHg}$.

Postoperative removal of the tracheal catheter was discussed by the anesthesiologist and the attending physician. When patients recovered spontaneous breathing, swallowing, cough reflex, VT $>6 \mathrm{~mL} / \mathrm{kg}$, oxygen saturation $\left(\mathrm{SpO}_{2}\right)>95 \%$ for $10 \mathrm{~min}$, gentle suction to clean the tube and oropharyngeal secretions, removal of the tracheal catheter, and delivery of oxygen by mask at $5 \mathrm{~L} /$ min were performed. The mask was removed $10 \mathrm{~min}$ later, followed by $20 \mathrm{~min}$ of observation, and then patients were sent to the ward. Others with tracheal catheter were directly sent to the ICU in the case of sedation, analgesia and ventilator.

\section{Outcomes}

The primary outcome was the incidence of 30-day total PPCs, which included hypoxemia, pulmonary infection, atelectasis, ARDS, VALI, and NPE. The definition of each PPC was as follows. (1) Hypoxemia: arterial partial pressure of oxygen $\left(\mathrm{PaO}_{2}\right)<60 \mathrm{mmHg}$ or $\mathrm{SpO}_{2}<90 \%$ in room air [7]. (2) Pulmonary infection: the clinical pulmonary infection score was greater than 6, and the symptoms of infection started before $48 \mathrm{~h}$ of respiratory treatment. (3) Atelectasis: the chest X-ray or computed tomography images showed lung opacification with a shift of the mediastinum, hilum or hemidiaphragm toward the affected area, and compensatory overinflation in the adjacent non-atelectatic lung. (4) ARDS: acute respiratory failure; $\mathrm{PaO}_{2} /$ fraction of inspired oxygen $\leq 300$ $\mathrm{mmHg}$; bilateral infiltrates on chest X-ray, and no signs of heart failure [8]. (5) VALI: mechanical ventilation $>$ $48 \mathrm{~h}$; pulmonary interstitial emphysema, pneumomediastinum, subcutaneous emphysema or pneumothorax, and infiltrates on chest X-ray. (6) NPE: the symptoms included dyspnea, tachypnea, cyanosis, and rales, crackles, or rhonchi. $\mathrm{PaO}_{2} /$ partial pressure of inspired oxygen $<$ 200; mild leukocytosis; bilateral alveolar opacities and diffuse alveolar infiltrates without cardiomegaly on chest X-ray [9].

Secondary outcomes were (1) intraoperative oxygenation and respiratory mechanics parameters $\left[\mathrm{PaO}_{2}\right.$, arterial partial pressure of carbon dioxide $\left(\mathrm{PaCO}_{2}\right)$, pulmonary dynamic compliance (Cdyn), airway peak pressure (Ppeak), Pplat, heart rate, mean arterial pressure (MAP)]; (2) the incidences of intraoperative pulmonary and cardiovascular adverse reactions $\left[\mathrm{SpO}_{2}<\right.$ $90 \%$ or $\mathrm{P}_{\mathrm{ET}} \mathrm{CO}_{2}>45 \mathrm{mmHg}$ or systolic blood pressure (SBP) $<90 \mathrm{mmHg}$ for more than $1 \mathrm{~min}$, any arrhythmia]; (3) intraoperative serum levels of brain injury markers [glial fibrillary acidic protein (GFAP), ubiquitin carboxylterminal hydrolase isozyme L1 (UCHL1)]; and (4) the 30-day postoperative incidences of pulmonary infection, hypoxemia, atelectasis, ARDS, VALI, NPE, intracranial infection, intracranial hypertension, epilepsy, encephaledema, and reoperation.

Other outcomes included intraoperative optic nerve sheath diameter (ONSD), postoperative duration of MV, length of stay, 30-day Glasgow Outcome Scale Extended (GOSE).

\section{Data collection}

The baseline characteristics were sex, age, BMI, ASA class, preoperative Glasgow Coma Scale score, hemoglobin concentration, intraoperative bleeding volume and infusion quantity, and total operative and anesthesia time.

Blood gas analysis was performed on a $1 \mathrm{~mL}$ radial artery blood sample at the onset of $\mathrm{MV}\left(\mathrm{T}_{1}\right)$, ventilation for $60 \mathrm{~min}\left(\mathrm{~T}_{2}\right)$, and the end of surgery $\left(\mathrm{T}_{3}\right)$. The ONSD was measured by color Doppler ultrasound at anesthesia induction $\left(\mathrm{T}_{0}\right), \mathrm{T}_{1}$, after applying $\operatorname{PEEP}\left(\mathrm{t}_{0}\right)$, before the first RM $\left(t_{1}\right)$, after the first RM $\left(t_{2}\right)$, before the second RM $\left(t_{3}\right)$, after the second RM $\left(t_{4}\right)$ and $T_{3}$. Five milliliters internal jugular vein blood sample of each patient at $\mathrm{T}_{1}$, $\mathrm{T}_{2}$ and $\mathrm{T}_{3}$ was placed in vacuum blood collection tubes, and the supernatant was collected and detected by ELISA Kit of GFAP and UCHL1 (ab223867, Abcam; CY-8092, CircuLex) according to the corresponding instructions. 


\section{Statistical analysis}

Sample size calculation was based on the previous report [10] and our pilot trial, which showed the incidence of total PPCs among the three groups was $86.7 \%, 53.3$ and $40.0 \%$, respectively. According to the calculation formula for the comparison of multiple sample rates $\left(n=\frac{1641.4 \lambda}{\left(\sin ^{-1} \sqrt{P_{\text {max }}}-\sin ^{-1} \sqrt{P_{\text {min }}}\right)^{2}}\right) \quad(\lambda=$ 12.65) [11], 23 patients per group were needed to detect a significant change in the incidence of total PPCs after applying LPV, with a type I error of 0.05 and $90 \%$ power.

Statistical Package for the Social Sciences version 22.0 was used for data processing. Normally distributed measurement data are expressed as the mean \pm standard deviation, and the Levene test was conducted to assess homogeneity. If the data met the hypothesis of equal variance, Student-Newman-Keuls was applied to compare differences between any two samples; otherwise, after performing the KruskalWallis $\mathrm{H}$ test, the Bonferroni method was utilized to correct the significance level for post-hoc multiple comparisons. Measurement data with skew distributions are expressed as medians and interquartile ranges, which were compared in the same way as data with unequal variances. Enumeration data expressed as percentages were analyzed by the Chi-square test for $\mathrm{R} \times \mathrm{C}$ table data. Pairwise comparisons were conducted if all theoretical frequencies were greater than 5; otherwise, Fisher's exact probability test and pairwise comparisons were conducted. $P<0.05$ was considered statistically significant.

\section{Results}

From December 2019 to September 2020, we recruited 90 eligible TBI patients and assigned them equally to receive conventional MV (Group A), small VT $+5 \mathrm{cmH}_{2} \mathrm{O}$ PEEP (Group B), and small VT $+5 \mathrm{cmH}_{2} \mathrm{O}$ PEEP + RMs (Group C). Finally, 79 participants completed the final analysis, as 5, 2 and 4 patients died within 30 days postoperatively in Groups A, B and C, respectively (Fig. 1). The baseline characteristics of the participants were comparable (Table 1).

Figure 2 shows the timeline of the intraoperative LPV strategy. Table 2 summarizes the intraoperative blood gas analysis, respiratory mechanics and hemodynamics. At $\mathrm{T}_{1}$, no significant differences in $\mathrm{PaO}_{2}, \mathrm{PaCO}_{2}, \mathrm{Cdyn}$, Ppeak or Pplat were detected among the three groups. At $\mathrm{T}_{2}$, compared to Group $\mathrm{A}$, the median $\mathrm{PaO}_{2}$ and Cdyn increased significantly in Groups B and C (336.0 vs. 375.5 vs. $388.0 \mathrm{mmHg}, P=0.028 ; 320.0$ vs. 360.0 vs. $\left.350.0 \mathrm{~mL} / \mathrm{cmH}_{2} \mathrm{O}, P=0.005\right)$, while their median Ppeak and Pplat decreased significantly (18.0 vs. 17.0 vs. 17.0 $\mathrm{cmH}_{2} \mathrm{O}, P=0.004 ; 14.0$ vs. 13.0 vs. $13.0 \mathrm{cmH}_{2} \mathrm{O}, P=$ 0.005). No significant difference in $\mathrm{PaCO}_{2}$ was detected. At $\mathrm{T}_{3}$, the median $\mathrm{PaO}_{2}, \mathrm{PaCO}_{2}$, and Cdyn in Groups $\mathrm{B}$ and $\mathrm{C}$ were higher than those in Group A (340.0 vs. 397.5 vs. $402.5 \mathrm{mmHg}, P=0.005 ; 40.0$ vs. 44.0 vs. 42.0 $\mathrm{mmHg}, P=0.025 ; 330.0$ vs. 340.0 vs. $340.0 \mathrm{~mL} / \mathrm{cmH}_{2} \mathrm{O}$, $P=0.009$ ), which was opposite to the median Ppeak and Pplat (19.0 vs. 17.0 vs. $17.0 \mathrm{cmH}_{2} \mathrm{O}, P=0.012 ; 16.0$ vs. 13.0 vs. $\left.14.0 \mathrm{cmH}_{2} \mathrm{O}, P=0.003\right)$. There were no significant differences in the aforementioned indicators between Groups $\mathrm{B}$ and $\mathrm{C}$ at either $\mathrm{T}_{2}$ or $\mathrm{T}_{3}$. Meanwhile,

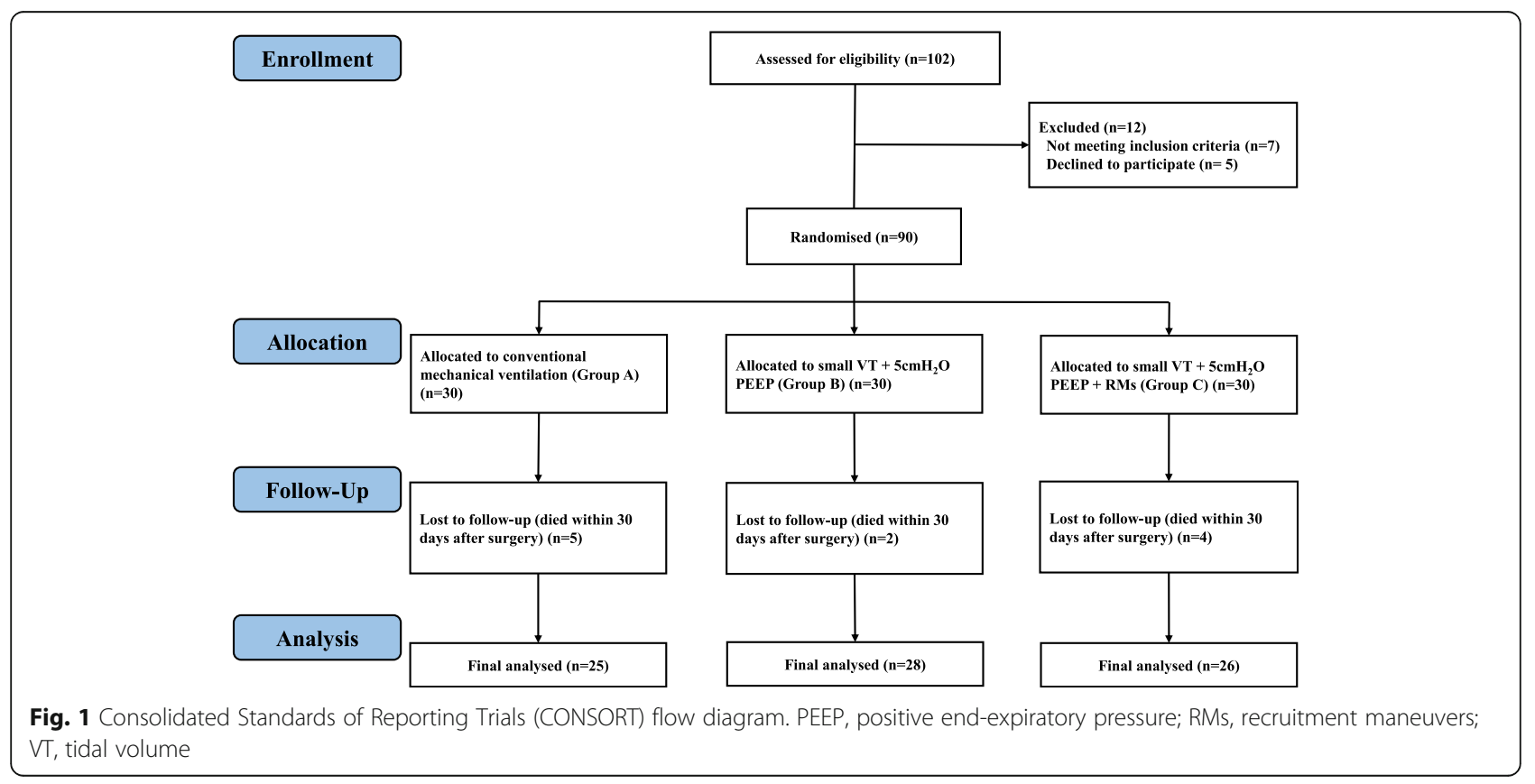


Table 1 Baseline characteristics by randomized group

\begin{tabular}{|c|c|c|c|c|}
\hline & Group A $(n=25)$ & Group B $(n=28)$ & Group C $(n=26)$ & $P$ \\
\hline \multicolumn{5}{|l|}{ Sex, n (\%) } \\
\hline Male & $17(68.0)$ & $20(71.4)$ & $20(76.9)$ & \multirow[t]{2}{*}{0.772} \\
\hline Female & $8(32.0)$ & $8(28.6)$ & $6(23.1)$ & \\
\hline Age, years, median (IQR) & $55.0(45.0-60.0)$ & $52.5(45.3-56.0)$ & $50.0(43.5-56.0)$ & 0.500 \\
\hline $\mathrm{BMI}, \mathrm{kg} / \mathrm{m}^{2}$, mean $\pm \mathrm{SD}$ & $23.3 \pm 2.1$ & $22.9 \pm 1.8$ & $22.6 \pm 1.8$ & 0.469 \\
\hline \multicolumn{5}{|l|}{ ASA Class, n (\%) } \\
\hline III & $9(36.0)$ & $7(25.0)$ & $7(26.9)$ & \multirow[t]{2}{*}{0.649} \\
\hline IV & $16(64.0)$ & $21(75.0)$ & $19(73.1)$ & \\
\hline \multicolumn{5}{|l|}{ Glasgow Coma Scale, n (\%) } \\
\hline $13-15$ & $1(4.0)$ & $3(10.7)$ & $3(11.5)$ & \multirow[t]{3}{*}{0.911} \\
\hline $9-12$ & $9(36.0)$ & $9(32.1)$ & $8(30.8)$ & \\
\hline$\leq 8$ & $15(60.0)$ & $16(57.1)$ & $15(57.7)$ & \\
\hline Preoperative hemoglobin, g/dL, median (IQR) & $12.0(10.0-13.0)$ & $13.0(11.3-13.8)$ & $12.0(11.0-13.3)$ & 0.462 \\
\hline Intraoperative amount of bleeding, mL, median (IQR) & $300.0(200.0-400.0)$ & $300.0(200.0-437.5)$ & $300.0(200.0-500.0)$ & 0.440 \\
\hline Intraoperative fluid infusion volume, $\mathrm{mL}$, median (IQR) & $\begin{array}{l}2500.0 \\
(1975.0-3175.0)\end{array}$ & $\begin{array}{l}2500.0 \\
(2000.0-3000.0)\end{array}$ & $\begin{array}{l}2500.0 \\
(2000.0-3000.0)\end{array}$ & 0.810 \\
\hline Operative time, min, median (IQR) & $200.0(150.0-237.5)$ & $177.5(156.3-199.5)$ & $162.5(150.0-222.5)$ & 0.379 \\
\hline Anesthesia time, min, median (IQR) & $245.0(200.0-285.0)$ & $220.0(201.3-253.8)$ & $202.5(193.8-270.0)$ & 0.508 \\
\hline
\end{tabular}

ASA American Society of Anesthesiologists; BMI body mass index; IQR interquartile range; SD standard deviation

${ }^{\text {a }}$ Glasgow Coma Scale score is an indicator used to assess the coma of a patient. It ranges from 3 to 15 , and the higher the score, the better the consciousness. Scores of $13-15,9-12$ and $\leq 8$ indicate mild, moderate and severe traumatic brain injury, respectively

heart rate and MAP among the three groups were comparable throughout the surgery.

Furthermore, intraoperative respiratory and cardiovascular adverse reactions were recorded and a 30-day postoperative follow-up was conducted (Table 3). Compared with that in Groups A and B, the incidence of intraoperative hypotension ( $\mathrm{SBP}<90 \mathrm{mmHg}$ ) in Group $\mathrm{C}$ increased significantly $(32.0 \%$ vs. $39.3 \%$ vs. $73.1 \%, P=$ 0.007 ), while no significant differences in the incidences of arrhythmia, $\mathrm{SpO}_{2}<90 \%$ and $\mathrm{P}_{\mathrm{ET}} \mathrm{CO}_{2}>45 \mathrm{mmHg}$ were found among the three groups. Our follow-up results showed that the incidences of total PPCs, hypoxemia, pulmonary infection and atelectasis in Groups B and $\mathrm{C}$ were significantly lower than those in Group A ( $84.0 \%$ vs. $57.1 \%$ vs. $53.8 \%, P=0.047 ; 52.0 \%$ vs. $14.3 \%$ vs. $19.2 \%, P=0.005 ; 84.0 \%$ vs. $50.0 \%$ vs. $42.3 \%, P=$ $0.006 ; 24.0 \%$ vs. $3.6 \%$ vs. $0.0 \%, P=0.004)$. However, the incidences of ARDS, VALI and NPE among the three groups were comparable. In addition, there were no significant differences in PPCs between Groups B and C. The postoperative incidences of neurological complications of the three groups were similar. The median postoperative ventilation time in Group A was significantly longer than that of Groups B and C (72.0 vs. 24.0 vs. $24.0 \mathrm{~h}, P=0.006$ ), which was comparable between the latter two groups. Likewise, there were no significant differences in GOSE score and hospital stay among the three groups.

For ONSD (Table 4), there were no significant differences among the three groups at $\mathrm{T}_{0}, \mathrm{~T}_{1}$ and $\mathrm{T}_{3}$. When compared within each group, the differences in Group A or B were comparable among time points. Comparisons in Group C were interesting. Specifically, after performing each RM, the mean ONSD $(\mathrm{mm})$ at $\mathrm{t}_{2}$ or $\mathrm{t}_{4}$ was not

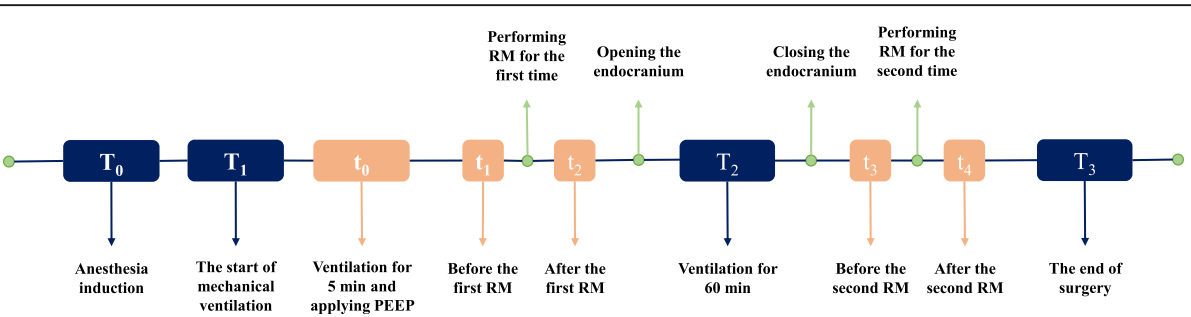

Fig. 2 Timeline of intraoperative lung-protective ventilation strategy implementation. PEEP, positive end-expiratory pressure; RM, recruitment maneuver 
Table 2 Intraoperative blood gas analysis, respiratory mechanics and hemodynamics

\begin{tabular}{|c|c|c|c|c|c|}
\hline & & Group A $(n=25)$ & Group B $(n=28)$ & Group C $(n=26)$ & $P$ \\
\hline \multirow[t]{3}{*}{$\mathrm{PaO}_{2}, \mathrm{mmHg}$} & $\mathrm{T}_{1}$ & $419.0(381.5-486.0)$ & $426.0(400.8-450.3)$ & 433.5 (367.5-487.3) & 0.781 \\
\hline & $\mathrm{T}_{2}$ & $436.0(382.0-487.0)$ & $475.5(447.3-496.8)^{*}$ & $488.0(409.8-527.3)^{*}$ & 0.028 \\
\hline & $T_{3}$ & 440.0 (394.5-493.5) & $497.5(486.8-534.5)^{\#}$ & $502.5(441.3-554.0)^{*}$ & 0.005 \\
\hline \multirow[t]{3}{*}{$\mathrm{PaCO}_{2}, \mathrm{mmHg}$} & $\mathrm{T}_{1}$ & $45.0(39.5-50.0)$ & $46.0(40.3-49.0)$ & $46.0(37.0-49.0)$ & 0.881 \\
\hline & $\mathrm{T}_{2}$ & $42.0(39.0-46.0)$ & $42.0(40.0-47.8)$ & $42.0(38.8-47.3)$ & 0.970 \\
\hline & $\mathrm{T}_{3}$ & $40.0(38.0-42.0)$ & $44.0(39.3-47.8)^{*}$ & $42.0(39.0-46.3)^{*}$ & 0.025 \\
\hline \multirow[t]{3}{*}{$\mathrm{Cdyn}, \mathrm{mL} / \mathrm{cmH}_{2} \mathrm{O}$} & $\mathrm{T}_{1}$ & $320.0(300.0-335.0)$ & 320.0 (310.0-350.0) & $310.0(300.0-322.5)$ & 0.080 \\
\hline & $T_{2}$ & $320.0(295.0-355.0)$ & $360.0(332.5-370.0)^{\#}$ & $350.0(340.0-360.0)^{*}$ & 0.005 \\
\hline & $\mathrm{T}_{3}$ & $330.0(305.0-345.0)$ & $340.0(330.0-360.0)^{*}$ & $340.0(330.0-370.0)^{*}$ & 0.009 \\
\hline \multirow[t]{3}{*}{ Ppeak, $\mathrm{cmH}_{2} \mathrm{O}$} & $\mathrm{T}_{1}$ & $17.0(16.0-20.0)$ & $18.0(16.0-19.0)$ & $19.0(17.0-20.0)$ & 0.379 \\
\hline & $\mathrm{T}_{2}$ & $18.0(17.5-21.0)$ & $17.0(16.0-18.8)^{\#}$ & $17.0(15.8-19.0)^{*}$ & 0.004 \\
\hline & $T_{3}$ & $19.0(18.0-21.0)$ & $17.0(15.3-20.0)^{*}$ & $17.0(16.0-19.0)^{*}$ & 0.012 \\
\hline \multirow[t]{3}{*}{ Pplat, $\mathrm{CmH}_{2} \mathrm{O}$} & $\mathrm{T}_{1}$ & $13.0(11.5-14.5)$ & $14.0(12.0-15.8)$ & $15.0(13.0-16.3)$ & 0.068 \\
\hline & $\mathrm{T}_{2}$ & $14.0(13.0-17.0)$ & $13.0(11.3-14.8)^{*}$ & $13.0(11.0-15.0)^{*}$ & 0.005 \\
\hline & $\mathrm{T}_{3}$ & $16.0(13.5-17.0)$ & $13.0(11.0-15.0)^{\#}$ & $14.0(11.8-15.3)^{*}$ & 0.003 \\
\hline \multirow[t]{3}{*}{ Heart rate, $\min ^{-1}$} & $\mathrm{~T}_{1}$ & $81(65-102)$ & $80(65-93)$ & 76 (72-92) & 0.779 \\
\hline & $\mathrm{T}_{2}$ & $66(58-92)$ & $70(62-87)$ & $68(62-83)$ & 0.891 \\
\hline & $T_{3}$ & $64(56-93)$ & $65(59-80)$ & $68(63-85)$ & 0.421 \\
\hline \multirow[t]{3}{*}{ MAP, $\mathrm{mmHg}^{\mathrm{a}}$} & $\mathrm{T}_{1}$ & $88.0(77.0-101.5)$ & $93.0(85.0-101.8)$ & $93.5(88.5-109.0)$ & 0.419 \\
\hline & $\mathrm{T}_{2}$ & $79.0(73.5-90.0)$ & 86.0 (77.0-95.0) & $82.0(73.8-86.5)$ & 0.210 \\
\hline & $T_{3}$ & $77.0(71.0-92.5)$ & 78.0 (71.3-84.3) & $81.0(72.0-91.5)$ & 0.802 \\
\hline
\end{tabular}

Data are presented as the median (interquartile range)

Cdyn pulmonary dynamic compliance; $D B P$ diastolic blood pressure; $M A P$ mean arterial pressure; $P a C O_{2}$ arterial partial pressure of carbon dioxide; $P a O_{2}$ arterial partial pressure of oxygen; Ppeak airway peak pressure; Pplat airway plateau pressure; SBP systolic blood pressure

${ }^{\mathrm{a}} \mathrm{MAP}=(\mathrm{SBP}+\mathrm{DBP} * 2) / 3$

${ }^{*} P<0.05,{ }^{\#} P<0.01$ compared to Group $A$ at the same point in time

only significantly higher than that before carrying out each RM ( $t_{1}$ vs. $t_{2}: 5.38$ vs. $5.65 ; t_{3}$ vs. $t_{4}: 5.38$ vs. 5.61 ; $P<0.05)$, but it was higher than that at $\mathrm{T}_{0}$ or $\mathrm{T}_{3}\left(\mathrm{~T}_{0}\right.$ vs. $\mathrm{t}_{2}: 5.26$ vs. $5.65 ; \mathrm{T}_{0}$ vs. $\mathrm{t}_{4}: 5.26$ vs. $5.61 ; \mathrm{T}_{3}$ vs. $\mathrm{t}_{2}: 5.34$ vs. $5.65 ; \mathrm{T}_{3}$ vs. $\mathrm{t}_{4}: 5.34$ vs. $\left.5.61 ; P<0.05\right)$.

Table 5 shows the serum levels of GFAP and UCHL1 in the three groups at different time points. Both of them increased significantly in each group with prolonged operative time $\left(P<0.001\right.$, each). At $\mathrm{T}_{1}$, there were no significant differences in GFAP or UCHL1 levels among the three groups. At $T_{2}$, the mean serum level of GFAP in Group B was the lowest ( 399.16 vs. 360.93 vs. $389.12 \mathrm{pg} / \mathrm{mL}, P=$ 0.042 ), but a significant difference was only detected between Group A and B. The mean serum level of UCHL1 in Group B was significantly lower than that in the other two groups $(828.16$ vs. 661.96 vs. $782.00 \mathrm{pg} / \mathrm{mL}, P=$ 0.001 ), which was comparable between Group A and C. Similarly, at $\mathrm{T}_{3}$, the mean serum level of GFAP was significantly lower in Group B than in the other groups (459.24 vs. 396.68 vs. $431.96 \mathrm{pg} / \mathrm{mL}, P=0.002$ ), which was comparable in the latter two groups. The mean serum level of UCHL1 was the highest in Group A and the lowest in Group B (1223.00 vs. 849.21 vs. 1068.50 pg/mL, $P<0.001)$.

\section{Discussion}

Our study investigated the effects of intraoperative LPV on respiratory function and the incidences of postoperative complications in emergency TBI patients. The results demonstrated that continuous intraoperative administration of small VT + PEEP could improve oxygenation and respiratory mechanics parameters, decrease the incidence of PPCs, and lower the increase in posttraumatic serum levels of brain injury markers. However, implementing intermittent RMs might disturb intraoperative cerebral hemodynamics, leading to fluctuations in ICP.

Small VT ventilation $(6-8 \mathrm{~mL} / \mathrm{kg} \mathrm{CBW})$ now serves as the respiratory care standard for ARDS patients in the ICU. A consensus has been formed that it is also suitable for patients with healthy lungs in the operating room $[12,13]$. An animal experiment showed that small VT ventilation could more effectively promote the oxygenation of rats with brain injury than large VT ventilation [14]. Furthermore, large VT ventilation in TBI patients 
Table 3 Intraoperative adverse reactions and 30-day postoperative follow-up

\begin{tabular}{|c|c|c|c|c|}
\hline & Group A $(n=25)$ & Group B $(n=28)$ & Group C $(n=26)$ & $P$ \\
\hline \multicolumn{5}{|l|}{ Intraoperative adverse reactions, n (\%) } \\
\hline $\mathrm{SpO}_{2}<90 \%$ & $2(8.0)$ & $1(3.6)$ & $1(3.8)$ & 0.685 \\
\hline $\mathrm{P}_{\mathrm{ET}} \mathrm{CO}_{2}>45 \mathrm{mmHg}$ & $1(4.0)$ & $5(17.9)$ & $5(19.2)$ & 0.213 \\
\hline $\mathrm{SBP}<90 \mathrm{mmHg}$ & $8(32.0)$ & $11(39.3)$ & $19(73.1)^{\mathrm{ab}}$ & 0.007 \\
\hline Arrhythmia & $2(8.0)$ & $5(17.9)$ & $4(15.4)$ & 0.609 \\
\hline \multicolumn{5}{|l|}{ Postoperative pulmonary complications, n (\%) } \\
\hline Total & $21(84.0)$ & $16(57.1)^{\mathrm{a}}$ & $14(53.8)^{a}$ & 0.047 \\
\hline Hypoxemia & $13(52.0)$ & $4(14.3)^{a}$ & $5(19.2)^{a}$ & 0.005 \\
\hline Pulmonary infection & $21(84.0)$ & $14(50.0)^{\mathrm{a}}$ & $11(42.3)^{a}$ & 0.006 \\
\hline Atelectasis & $6(24.0)$ & $1(3.6)^{\mathrm{a}}$ & $0(0.0)^{\mathrm{a}}$ & 0.004 \\
\hline Acute respiratory distress syndrome & $1(4.0)$ & $1(3.6)$ & $0(0.0)$ & 0.764 \\
\hline Ventilator-associated lung injury & $3(12.0)$ & $3(10.7)$ & $2(7.7)$ & 0.902 \\
\hline Neurogenic pulmonary edema & $1(4.0)$ & $0(0.0)$ & $1(3.9)$ & 0.537 \\
\hline \multicolumn{5}{|l|}{ Postoperative neurological complications, n (\%) } \\
\hline Intracranial infection & $3(12.0)$ & $3(10.7)$ & $4(15.4)$ & 0.915 \\
\hline Intracranial hypertension & $6(24.0)$ & $7(25.0)$ & $7(26.9)$ & 1.000 \\
\hline Epilepsy & $2(8.0)$ & $2(7.1)$ & $3(11.5)$ & 0.890 \\
\hline Encephaledema & $5(20.0)$ & $5(17.9)$ & $6(23.1)$ & 0.939 \\
\hline Reoperation & $2(8.0)$ & $1(3.6)$ & $2(7.7)$ & 0.733 \\
\hline \multicolumn{5}{|l|}{ Other } \\
\hline Mechanical ventilation time, $h$, median (interquartile range) & $72.0(36.0-105.0)$ & $24.0(3.0-62.0)^{a}$ & $24.0(9.1-66.0)^{a}$ & 0.006 \\
\hline Length of stay, days, mean $\pm S D$ & $21.5 \pm 10.4$ & $21.9 \pm 8.3$ & $22.0 \pm 7.5$ & 0.975 \\
\hline GOSE score, mean \pm SD $^{c}$ & $5 \pm 1.6$ & $6 \pm 1.3$ & $5 \pm 1.2$ & 0.768 \\
\hline
\end{tabular}

GOSE Glasgow Outcome Scale Extended; $P_{E T} C_{2}$ end-tidal carbon dioxide partial pressure; $S B P$ systolic blood pressure; $S D$ standard deviation; $\mathrm{SpO}_{2}$ oxygen saturation

${ }^{\mathrm{a}} P<0.05$ compared to Group $\mathrm{A} ;{ }^{\mathrm{b}} P<0.05$ compared to Group B

' GOSE is used to assess outcomes of patients with brain damage and is divided into 8 levels. The higher the grade, the better the patient's prognosis is

might be associated with the occurrence of ARDS, and its incidence increased to some extent with VT [15]. However, a single use of small VT causes periodic alveolar collapse of local lung tissues, thus increasing the risk of atelectasis. Interestingly, this adverse effect can be offset by combining PEEP and/or RMs, which would inevitably involve positive pressure ventilation and might adversely affect ICP and CPP [16-18]. However, another study showed that high PEEP $\left(5-15 \mathrm{cmH}_{2} \mathrm{O}\right)$ could improve $\mathrm{PaO}_{2}$ of local brain tissue without affecting ICP and CPP in patients with TBI and ARDS [19]. In summary, the interaction between the lung and the brain poses an important challenge to ventilation management in TBI patients. The optimal ventilation strategy for TBI patients requires in-depth discussion.

In this study, two groups of TBI patients were treated with LPV: small VT ( $8 \mathrm{~mL} / \mathrm{kg} \mathrm{CBW})$, intraoperative continuous administration of $5 \mathrm{cmH}_{2} \mathrm{O}$ PEEP. Some were given RMs before opening and after closing the endocranium. Our results showed that intraoperative application of small VT + PEEP or small VT + PEEP + RMs improved oxygenation and pulmonary compliance in TBI patients compared to those treated with conventional MV. However, no significant differences in $\mathrm{PaO}_{2}$ and

Table 4 Ultrasound measurement of ONSD

\begin{tabular}{|c|c|c|c|c|c|c|c|c|c|}
\hline & $T_{0}$ & $\mathrm{~T}_{1}$ & $t_{0}$ & $t_{1}$ & $t_{2}$ & $t_{3}$ & $t_{4}$ & $T_{3}$ & $P$ \\
\hline Group A $(n=25)$ & $5.32 \pm 0.36$ & $5.37 \pm 0.32$ & NA & NA & NA & NA & NA & $5.32 \pm 0.30$ & 0.864 \\
\hline Group B $(n=28)$ & $5.33 \pm 0.32$ & $5.37 \pm 0.30$ & $5.44 \pm 0.31$ & NA & NA & NA & NA & $5.38 \pm 0.29$ & 0.527 \\
\hline Group C $(n=28)$ & $5.26 \pm 0.28$ & $5.32 \pm 0.30$ & $5.37 \pm 0.31$ & $5.38 \pm 0.29$ & $5.65 \pm 0.28^{\mathrm{abcd}}$ & $5.38 \pm 0.30$ & $5.61 \pm 0.28^{\mathrm{abcd}}$ & $5.34 \pm 0.29$ & $<0.001$ \\
\hline
\end{tabular}

Data are presented as the mean \pm standard deviation $(\mathrm{mm})$

NA not applicable; ONSD optic nerve sheath diameter

${ }^{\mathrm{a}} P<0.05,{ }^{\mathrm{b}} P<0.05,{ }^{\mathrm{c}} P<0.05,{ }^{\mathrm{d}} P<0.05$ compared to $\mathrm{T}_{0}, \mathrm{~T}_{3}, \mathrm{t}_{1}, \mathrm{t}_{3}$, respectively 
Table 5 Intraoperative serum levels of GFAP and UCHL1

\begin{tabular}{|c|c|c|c|c|c|}
\hline & & Group A $(n=25)$ & Group B $(n=28)$ & Group C $(n=26)$ & $P$ \\
\hline \multirow[t]{3}{*}{ GFAP } & $\mathrm{T}_{1}$ & $328.68 \pm 54.50$ & $325.79 \pm 55.82$ & $336.58 \pm 61.04$ & 0.776 \\
\hline & $\mathrm{T}_{2}$ & $399.16 \pm 55.40^{*}$ & $360.93 \pm 56.71^{1^{*}}$ & $389.12 \pm 57.32^{*}$ & 0.042 \\
\hline & $T_{3}$ & $459.24 \pm 56.37^{* \#}$ & $396.68 \pm 55.78^{\mathrm{a}^{* \#}}$ & $431.96 \pm 71.44^{b^{* \#}}$ & 0.002 \\
\hline \multirow[t]{3}{*}{ UCHL1 } & $\mathrm{T}_{1}$ & $422.60 \pm 165.27$ & $413.43 \pm 172.77$ & $434.58 \pm 186.98$ & 0.906 \\
\hline & $\mathrm{T}_{2}$ & $828.16 \pm 134.20^{*}$ & $661.96 \pm 166.73^{\mathrm{a}^{*}}$ & $782.00 \pm 177.36^{\mathrm{b}^{*}}$ & 0.001 \\
\hline & $T_{3}$ & $1223.00 \pm 126.37^{* \#}$ & $849.21 \pm 175.51^{a^{* \# \#}}$ & $1068.50 \pm 167.71^{a b^{* \#}}$ & $<0.001$ \\
\hline
\end{tabular}

Data are presented as the mean \pm standard deviation $(\mathrm{pg} / \mathrm{mL})$

GFAP glial fibrillary acidic protein; UCHL1 ubiquitin carboxyl-terminal hydrolase isozyme L1

${ }^{\mathrm{a} P} P<0.05$ compared to Group $A,{ }^{b} P<0.05$ compared to Group $B$ at the same point in time

${ }^{*} P<0.05,{ }^{\#} P<0.05$ compared to $T_{1}$ and $T_{2}$ within each group

Cdyn were found between two intervention groups, suggesting that RMs might not provide further improvement on the basis of PEEP. Ppeak, close to airway pressure, reflects the dynamic compliance of respiratory system. Recently, Pplat was recommended as a better predictor of barotrauma and VALI, as it is closer to alveolar pressure and reflects the static compliance of the respiratory system [20]. Our results showed that patients who intervened with LPV had lower Ppeak and Pplat than those receiving conventional MV, suggesting that the implementation of LPV improved respiratory mechanics parameters and contributed to relieving barotrauma and PPCs. However, there was a rise in $\mathrm{PaCO}_{2}$ at the end of surgery in patients receiving LPV, which may be explained by $\mathrm{CO}_{2}$ retention resulted from reduced periodic alveolar collapse and expansion following small VT. However, the small rise could be considered a compensatory state that would not cause obvious pathological damage [21]. The incidence of intraoperative hypoxemia was lower in the two intervention groups, while cardiovascular adverse reactions were more frequently observed in the small VT + PEEP + RMs group. Since intrathoracic pressure increased rapidly in a short time, RMs-treated patients generated a decrease in blood volume returning to the heart and cardiac output [16]. Collectively, although small VT + PEEP + RMs can improve intraoperative oxygenation and respiratory mechanics parameters in TBI patients, RMs may cause adverse effects on hemodynamics, while small VT only combined with PEEP can improve lung function without affecting their circulatory stability.

PPCs are the most common mid-term complications after major surgery and strongly linked to clinical prognosis [22]. An observational study in 29 countries named LAS VEGAS showed that $80 \%$ severe TBI patients developed PPCs [7]. Serious pulmonary complications, like ARDS, NPE or VALI, are associated with high mortality, unfavorable neurological outcomes, longer ICU retention and longer hospital stays in TBI patients [23]. We investigated the incidence of pulmonary complications within 30 days postoperatively. The incidences of total
PPCs, hypoxemia, pulmonary infection, and atelectasis in LPV-intervened patients were significantly lower than those in patients receiving conventional MV, which was consistent with the Marret E et al. [24] study. Moreover, using LPV significantly reduced postoperative ventilation time, which might be attributed to the improvement of intraoperative respiratory function and decreased risk of PPCs by small VT combined with PEEP and RMs. The GOSE score is usually used to evaluate the degree of disability and neurological prognosis of TBI patients [25]. Our results showed no significant differences in GOSE scores among the three groups after 30 days, probably owing to a short follow-up time and limited sample size. Postoperative neurological complications and hospital stays were comparable among the three groups, possibly because improving the ventilation strategy alone hardly achieved a breakthrough in the neurological outcomes of TBI patients. Surgical factors, the quality of nursing, and family economical state all need to be considered comprehensively.

The greatest concern about TBI patients with respect to perioperative LPV is that it may have an adverse effect on ICP and CPP. Ultrasound measurement of ONSD is a novel noninvasive method that is widely used to dynamically and rapidly assess changes in ICP. It has a close correlation with canonical direct intubation in the ventricle to estimate intracranial hypertension [26, 27]. Our ultrasound results showed no significant changes in ONSD at any time in either conventional MV or small $\mathrm{VT}+\mathrm{PEEP}$ group, suggesting that intraoperative continuous administration of $5 \mathrm{cmH}_{2} \mathrm{O}$ PEEP did not affect patients' ICP. Mascia et al. [15] randomly applied 5 $\mathrm{cmH}_{2} \mathrm{O}$ or $10 \mathrm{cmH}_{2} \mathrm{O}$ PEEP in 12 patients along with brain injury and ARDS. They found that the PEEP level, which was insufficient to give rise to excessive alveolar expansion or an evident increase in $\mathrm{PaCO}_{2}$, had no significant impact on ICP and could safely improve oxygenation. Likewise, if the PEEP value was lower than ICP during $\mathrm{MV}$, the elevation of intrathoracic pressure within a certain range would not increase ICP [28]. Therefore, $5 \mathrm{cmH}_{2} \mathrm{O}$ PEEP was applied in our study, not 
visibly increasing ICP, because it did not cause alveolar hyperinflation or it was less than patients' ICP. However, RMs could rapidly expand the alveoli in a short period and increase the pressure in the thoracic cavity, which blocked the return of systemic circulation to the right atrium (cerebral venous reflux) and eventually increased ICP. After ceasing RMs, the intrathoracic pressure dropped to normal, and the patient's ICP decreased accordingly [29]. Consistent with previous findings [30], a single RM transiently increased ONSD, which returned to the baseline within 5-10 min, indicating that RMs had the risk of elevating ICP in TBI patients.

Immediately after acute brain injury, astrocytes undergo mechanical deformation or local necrosis, leading to an increased serum concentration of GFAP [3133]. UCHL1 is a neuron-specific cytosolic enzyme, and its serum level in acute phase of cerebral injury is strongly correlated with the severity of damage [34]. Combined testing of GFAP and UCHL1 could more accurately diagnose the severity of brain damage and predict the long-term prognosis [35]. Here, postoperative serum levels of GFAP and UCHL1 in each group were higher than before. This may be because they were released from necrotic cells and accumulated with the posttraumatic time course [36]. Furthermore, both serum levels of GFAP and UCHL1 in Group B were lower than those in the other groups at $\mathrm{T}_{3}$. PEEP can improve oxygenation and reduce the release of inflammatory mediators from the lung and brain, thereby alleviating secondary injuries. Interestingly, additional RMs posed a large continuous positive airway pressure in a short time, which had an adverse effect on cerebral hemodynamics that neutralized favorable results of implementing PEEP. Hence, intraoperative application of small VT + PEEP could prevent further brain damage in TBI patients to some extent. Whether RMs played the same role remained further exploration.

Several limitations in our study should be noted. First and foremost, this study reported the results of a health care intervention on human participants, which should be registered before enrollment of the first participant. We must acknowledge our negligence of the prospective registration, and made a retrospective registration to complete our unfulfilled registration obligations and responsibilities. Second, actual values and accurate changes in ICP were unable to be obtained from ultrasound measurement of ONSD. Third, our results may not be applicable to other neurosurgical patients, such as those with intracranial tumors, craniocerebral injury in the sitting position during surgery, spontaneous cerebral hemorrhage, etc. Fourth, during the study period, especially before the operation, some severe patients were treated with mannitol and dexamethasone due to their conditions, which might consequently affect the results. Fifth, the 30-day postoperative follow-up was unable to accurately evaluate the long-term survival and quality of life of TBI patients. Last, it was a single-center study with a limited sample size. Large-scale clinical trials are needed in the future to validate the impact of intraoperative LPV on TBI patients.

\section{Conclusions}

Intraoperative continuous administration of small VT + PEEP is beneficial to TBI patients, manifesting as improved oxygenation and respiratory mechanics parameters, decreased incidences of PPCs, and smaller increases in posttraumatic serum levels of brain injury markers. However, additional RMs should be cautiously applied in these patients, since they are prone to disturbing intraoperative cerebral hemodynamics.

\section{Abbreviations \\ TBI: Traumatic brain injury; NPE: Neurogenic pulmonary edema; VALI: Ventilator-associated lung injury; VT: Tidal volume; CBW: Corrected body weight; LPV: Lung-protective ventilation; PEEP: Positive end-expiratory pressure; Pplat: Airway plateau pressure; ARDS: Acute respiratory distress syndrome; ICU: Intensive care unit; MV: Mechanical ventilation; PPCs: Postoperative pulmonary complications; RMs: Recruitment maneuvers; ICP: Intracranial pressure; CPP: Cerebral perfusion pressure; BMI: Body mass index; ASA: American Society of Anesthesiologists; $\mathrm{P}_{\mathrm{ET}} \mathrm{CO}_{2}$ : End-tidal carbon dioxide partial pressure; $\mathrm{SpO}_{2}$ : Oxygen saturation; $\mathrm{PaO}_{2}$ : Arterial partial pressure of oxygen; $\mathrm{PaCO}_{2}$ : Arterial partial pressure of carbon dioxide; Cdyn: Pulmonary dynamic compliance; Ppeak: Airway peak pressure; MAP: Mean arterial pressure; SBP: Systolic blood pressure; GFAP: Glial fibrillary acidic protein; UCHL1: Ubiquitin carboxyl-terminal hydrolase isozyme L1; ONSD: Optic nerve sheath diameter; GOSE: Glasgow Outcome Scale Extended}

\section{Acknowledgements}

Not applicable.

\section{Authors' contributions}

$J G, L L J$ and YJW have given substantial contributions to the conception and design of the manuscript, YZ, DHL and KSY to acquisition, analysis and interpretation of the data. All authors have participated in drafting the manuscript, JG and $L L J$ revised it critically. All authors read and approved the final manuscript.

\section{Funding}

None.

\section{Availability of data and materials}

The datasets used and/or analyzed during the current study are available from the corresponding author on reasonable request.

\section{Declarations}

Ethics approval and consent to participate

This study was approved by the Ethical Committee of Northern Jiangsu People's Hospital (2019113). All procedures performed involving human participants were in accordance with the ethical standards of the Declaration of Helsinki 1964 and its later amendments. Informed consent was obtained from all individual participants included in the study or their relatives.

Consent for publication

Not applicable.

Competing interests

The authors declare that they have no competing interests. 


\section{Author details}

${ }^{1}$ Department of Anesthesiology, the Second Xiangya Hospital, Central South University, 139\# Renmin Central Road, 410011 Changsha, China. ${ }^{2}$ Department of Anesthesiology, Northern Jiangsu People's Hospital, Clinical Medical School, Yangzhou University, 98\# Nantong West Road, 225001 Yangzhou, China. ${ }^{3}$ Department of Anesthesiology, Xiangtan Central Hospital, 120\# Heping Road, 411100 Xiangtan, China.

\section{Received: 15 December 2020 Accepted: 15 June 2021} Published online: 28 June 2021

\section{References}

1. Maas A, Menon DK, Adelson PD, Andelic N, Bell MJ, Belli A, et al. Traumatic brain injury: integrated approaches to improve prevention, clinical care, and research. Lancet Neurol. 2017;16(12):987-1048.

2. Zygun DA, Kortbeek JB, Fick GH, Laupland KB, Doig CJ. Non-neurologic organ dysfunction in severe traumatic brain injury. Crit Care Med. 2005; 33(3):654-60.

3. Koutsoukou A, Katsiari M, Orfanos SE, Kotanidou A, Daganou M, Kyriakopoulou M, et al. Respiratory mechanics in brain injury: A review. World J Crit Care Med. 2016;5(1):65-73.

4. Lopez-Aguilar J, Quilez ME, Marti-Sistac O, Garcia-Martin C, Fuster G, Puig F, et al. Early physiological and biological features in three animal models of induced acute lung injury. Intensive Care Med. 2010;36(2):347-55.

5. Fan E, Brodie D, Slutsky AS. Acute Respiratory Distress Syndrome: Advances in Diagnosis and Treatment. JAMA. 2018;319(7):698-710.

6. Boone MD, Jinadasa SP, Mueller A, Shaefi S, Kasper EM, Hanafy KA, et al. The Effect of Positive End-Expiratory Pressure on Intracranial Pressure and Cerebral Hemodynamics. Neurocrit Care. 2017;26(2):174-81.

7. Epidemiology, practice of ventilation and outcome for patients at increased risk of postoperative pulmonary complications: LAS VEGAS - an observational study in 29 countries. Eur J Anaesthesiol. 2017;34(8):492-507.

8. Schirmer-Mikalsen K, Moen KG, Skandsen T, Vik A, Klepstad P. Intensive care and traumatic brain injury after the introduction of a treatment protocol: a prospective study. Acta Anaesthesiol Scand. 2013;57(1):46-55.

9. Finsterer J. Neurological Perspectives of Neurogenic Pulmonary Edema. Eur Neurol. 2019;81(1-2):94-102.

10. Kerr N, de Rivero Vaccari JP, Dietrich WD, Keane RW. Neural-respiratory inflammasome axis in traumatic brain injury. Exp Neurol. 2020;323:113080.

11. Sun ZQ. Estimation of Sample Size. In: Sun ZQ, Xu YY, Ma J, editors. Medical Statistics. 4th ed. Beijing: People's Medical Publishing House; 2014. p. 57383.

12. Futier E, Constantin JM, Paugam-Burtz C, Pascal J, Eurin M, Neuschwander A, et al. A trial of intraoperative low-tidal-volume ventilation in abdominal surgery. N Engl J Med. 2013;369(5):428-37.

13. O'Gara B, Talmor D. Perioperative lung protective ventilation. BMJ. 2018;362: k3030.

14. Krebs J, Tsagogiorgas C, Pelosi P, Rocco PR, Hottenrott M, Sticht C, et al. Open lung approach with low tidal volume mechanical ventilation attenuates lung injury in rats with massive brain damage. Crit Care. 2014; 18(2):R59.

15. Mascia L, Zavala E, Bosma K, Pasero D, Decaroli D, Andrews P, et al. High tidal volume is associated with the development of acute lung injury after severe brain injury: an international observational study. Crit Care Med. 2007:35(8):1815-20.

16. Ruggieri F, Beretta L, Corno L, Testa V, Martino EA, Gemma M. Feasibility of Protective Ventilation During Elective Supratentorial Neurosurgery: A Randomized, Crossover, Clinical Trial. J Neurosurg Anesthesiol. 2018;30(3): 246-50

17. Georgiadis D, Schwarz S, Baumgartner RW, Veltkamp R, Schwab S. Influence of positive end-expiratory pressure on intracranial pressure and cerebral perfusion pressure in patients with acute stroke. Stroke. 2001;32(9):2088-92.

18. Bein T, Kuhr LP, Bele S, Ploner F, Keyl C, Taeger K. Lung recruitment maneuver in patients with cerebral injury: effects on intracranial pressure and cerebral metabolism. Intensive Care Med. 2002;28(5):554-8.

19. Nemer SN, Caldeira JB, Santos RG, Guimaraes BL, Garcia JM, Prado D, et al. Effects of positive end-expiratory pressure on brain tissue oxygen pressure of severe traumatic brain injury patients with acute respiratory distress syndrome: A pilot study. J Crit Care. 2015;30(6):1263-6.
20. Chan MC, Tseng JS, Chiu JT, Hsu KH, Shih SJ, Yi CY, et al. Prognostic value of plateau pressure below $30 \mathrm{~cm} \mathrm{H2O}$ in septic subjects with acute respiratory failure. Respir Care. 2015;60(1):12-20.

21. Barnes T, Zochios V, Parhar K. Re-examining Permissive Hypercapnia in ARDS: A Narrative Review. Chest. 2018;154(1):185-95.

22. Jammer I, Wickboldt N, Sander M, Smith A, Schultz MJ, Pelosi P, et al. Standards for definitions and use of outcome measures for clinical effectiveness research in perioperative medicine: European Perioperative Clinical Outcome (EPCO) definitions: a statement from the ESA-ESICM joint taskforce on perioperative outcome measures. Eur J Anaesthesiol. 2015; 32(2):88-105.

23. Steyerberg EW, Wiegers E, Sewalt C, Buki A, Citerio G, De Keyser V, et al. Case-mix, care pathways, and outcomes in patients with traumatic brain injury in CENTER-TBI: a European prospective, multicentre, longitudinal, cohort study. Lancet Neurol. 2019;18(10):923-34.

24. Marret E, Cinotti R, Berard L, Piriou V, Jobard J, Barrucand B, et al. Protective ventilation during anaesthesia reduces major postoperative complications after lung cancer surgery: A double-blind randomised controlled trial. Eur J Anaesthesiol. 2018;35(10):727-35.

25. Zelnick LR, Morrison LJ, Devlin SM, Bulger EM, Brasel KJ, Sheehan K, et al. Addressing the challenges of obtaining functional outcomes in traumatic brain injury research: missing data patterns, timing of follow-up, and three prognostic models. J Neurotrauma. 2014;31(11):1029-38.

26. Whiteley JR, Taylor J, Henry M, Epperson TI, Hand WR. Detection of elevated intracranial pressure in robot-assisted laparoscopic radical prostatectomy using ultrasonography of optic nerve sheath diameter. J Neurosurg Anesthesiol. 2015;27(2):155-9.

27. Cammarata G, Ristagno G, Cammarata A, Mannanici G, Denaro C, Gullo A. Ocular ultrasound to detect intracranial hypertension in trauma patients. Trauma. 2011;71(3):779-81.

28. Chen H, Menon DK, Kavanagh BP. Impact of Altered Airway Pressure on Intracranial Pressure, Perfusion, and Oxygenation: A Narrative Review. Crit Care Med. 2019:47(2):254-63.

29. Nemer SN, Caldeira JB, Azeredo LM, Garcia JM, Silva RT, Prado D, et al. Alveolar recruitment maneuver in patients with subarachnoid hemorrhage and acute respiratory distress syndrome: a comparison of 2 approaches. J Crit Care. 2011;26(1):22-7.

30. Lyon M, Agrawal P, Friez K, Gordon R, Morales I, Fang ZL, et al. Effect of History of Mild Traumatic Brain Injury on Optic Nerve Sheath Diameter Changes after Valsalva Maneuver. J Neurotrauma. 2018;35(4):695-702.

31. Nylen K, Ost M, Csajbok LZ, Nilsson I, Blennow K, Nellgard B, et al. Increased serum-GFAP in patients with severe traumatic brain injury is related to outcome. J Neurol Sci. 2006;240(1-2):85-91.

32. Czeiter E, Mondello S, Kovacs N, Sandor J, Gabrielli A, Schmid K, et al. Brain injury biomarkers may improve the predictive power of the IMPACT outcome calculator. J Neurotrauma. 2012;29(9):1770-8.

33. McMahon PJ, Panczykowski DM, Yue JK, Puccio AM, Inoue T, Sorani MD, et al. Measurement of the glial fibrillary acidic protein and its breakdown products GFAP-BDP biomarker for the detection of traumatic brain injury compared to computed tomography and magnetic resonance imaging. J Neurotrauma. 2015;32(8):527-33.

34. Li J, Yu C, Sun Y, Li Y. Serum ubiquitin C-terminal hydrolase L1 as a biomarker for traumatic brain injury: a systematic review and meta-analysis. Am J Emerg Med. 2015;33(9):1191-6.

35. Mondello $\mathrm{S}$, Jeromin A, Buki A, Bullock R, Czeiter E, Kovacs N, et al. Glial neuronal ratio: a novel index for differentiating injury type in patients with severe traumatic brain injury. J Neurotrauma. 2012;29(6):1096-104.

36. Papa L, Brophy GM, Welch RD, Lewis LM, Braga CF, Tan CN, et al. Time Course and Diagnostic Accuracy of Glial and Neuronal Blood Biomarkers GFAP and UCH-L1 in a Large Cohort of Trauma Patients With and Without Mild Traumatic Brain Injury. JAMA Neurol. 2016;73(5):551-60.

\section{Publisher's Note}

Springer Nature remains neutral with regard to jurisdictional claims in published maps and institutional affiliations. 